\title{
Literatura chilena de la postransición: Una lectura a los determinantes sociopolíticos de la narrativa de Eltit y Fuguet ${ }^{*}$
}

\author{
Chilean Post-Transition Literature: A Reading of the Socio- \\ Political Attachments of Eltit and Fuguet's Narrative Fiction
}

Denisse Lazo-González ${ }^{* *}$

\section{RESUMEN}

Este trabajo examina la relación entre literatura y política, proponiendo una mirada de la literatura chilena publicada a partir del año 2000 como literatura de la postransición. Toma como ejemplos semicanónicos a Diamela Eltit y Alberto Fuguet, enfocándose en sus novelas Fuerzas especiales y Aeropuertos, respectivamente; en particular, en los medios modernos de control social y potenciales vías para resistirlo que sugieren estas obras. El artículo tiene como objetivos desvelar las maneras en que las representaciones literarias de dos autores - aparentemente disímiles como Eltit y Fuguet- interactúan con determinantes sociopolíticos propios de la postransición chilena, y demostrar el rol político-cultural que dicha literatura juega en la creación de un cierto imaginario social de la postransición, más allá de las diferentes perspectivas con las que los autores puedan contribuir.

\begin{abstract}
This work examines the politics of literature by proposing a view of literature published in Chile after the year 2000 as representative of Chile's post-transition literature. It takes Diamela Eltit and Alberto Fuguet as semi-canonical examples and focuses its analysis on the novels Fuerzas Especiales and Aeropuertos, and
\end{abstract}

Palabras clave: literatura y política, literatura chilena de la postransición, Eltit, Fuguet, literatura e imaginario social.
Keywords: politics of literature, posttransition Chilean literature, Eltit,

Este trabajo es parte de la investigación doctoral titulada "The Politics of Literature in Chilean Post-Transition to Democracy Novels: Portraits of Society and the Political Status of Women in the Narrative of Diamela Eltit and Alberto Fuguet", llevada a cabo en la Univesidad de Oxford y financiada por Conicyt.

** Chilena, Doctora por la Universidad de Oxford, Teaching Fellow, Universidad de Reading, Reading, Reino Unido d.lazo-gonzalez@reading.ac.uk 
specifically on the modern means of social control and the potential paths towards resistance as suggested by these novels. The article aims to unveil the ways in which these authors' seemingly different literary representations interact with the socio-political attachments of the Chilean post-transition, as well as to demonstrate the political and cultural role that this kind of literature plays in the creation of a certain post-transition social imaginary, regardless of the author's different standpoints.
Fuguet, literature and social imaginary 


\section{Literatura, política y transición en Chile}

Para llevar a cabo una lectura sociopolítica de la literatura más reciente de dos autores aparentemente disímiles como Diamela Eltit (1949) y Alberto Fuguet (1964-) es necesario indagar en la relación entre literatura y política, para lo cual es relevante comenzar por trazar la interconexión entre la ficción literaria y el imaginario social. John Thompson define el imaginario social como "La dimensión creativa y simbólica del mundo social, la dimensión a través de la cual los seres humanos crean sus formas de vivir en conjunto y sus maneras de representar la vida colectiva" ${ }^{1}$ (Thompson 6 ). El imaginario social se expresa mediante significaciones que, con su naturaleza creativa, dotan a una sociedad de identidad para distinguirla de otras (24). En cuanto a esto, Cornelius Castoriadis considera a la sociedad en sí una institución que constituye un magma de significaciones del imaginario social, lo que él llama "mundo de significaciones" (Castoriadis 359). Los simbolismos que son parte de tales significaciones se ligan al mundo real y unen a una determinada sociedad en cuanto a lo que esta considera como "realidad" en un periodo dado (359-371). De particular relevancia para el estudio de la relación entre política y literatura, el simbolismo de tales significaciones encuentra especial resonancia en el lenguaje, el que contribuye a determinar la manera en que se organizan este mundo de significaciones y la realidad, esto es, la forma en que una determinada sociedad percibe su existencia en un periodo histórico determinado (371).

De este modo, el imaginario social es una de las fuerzas reguladoras de la vida colectiva. Siguiendo a Bronislaw Baczko, solo existe comunicación entre las personas por medio de símbolos exteriores a los estados mentales individuales, símbolos tomados como realidades, elegidos más o menos de manera arbitraria (Baczko 21). Estas nociones conectan al imaginario social con el ejercicio del poder al rodearse este último - especialmente el político-de representaciones colectivas en lo imaginario y lo simbólico (12-30). Este enfoque es especialmente relevante para el estudio de la literatura y su relación con lo sociopolítico, al enmarcar la forma en que los mensajes y significados vehiculizados por el lenguaje literario pueden nutrir o informar un cierto imaginario

Traducción propia. 
social, no solo como representación de formas de vida colectiva, sino como impulso que influye en la manera en que la imaginamos. Así, en una dinámica interconectada, en su naturaleza ficcional la literatura contribuye a la creación de un cierto imaginario social y a la diseminación de creencias y valores culturales, y de las relaciones de poder que forman parte de él.

Idelber Avelar entiende que la transición chilena comenzó el 11 de septiembre de 1973 con el golpe militar que derrocó a Salvador Allende, presidente socialista democráticamente electo. La refundación capitalista de Chile no podría haberse llevado a cabo en democracia y, por lo tanto, la dictadura fue el comienzo de la transición, es decir, del inicio de la transformación hacia el actual sistema neoliberal que rige a Chile (Avelar 29, 78, 81).

El neoliberalismo se refiere a las políticas económicas que favorecen una reducción del rol del Estado y del gasto público, así como la privatización de sus activos. Otras características son la tecnificación de la gobernabilidad, la despolitización de la sociedad y un afán de reinstaurar el poder de clase en las manos de las elites empresariales (Undurraga 13-14). En Chile, la doctrina del libre mercado se implementó en dictadura bajo el liderazgo de los llamados Chicago Boys, un grupo de tecnócratas educados en las aulas del Departamento de Economía de la Universidad de Chicago, al alero de las enseñanzas de Milton Friedman y sus principios de libertad económica. Bajo condiciones de impunidad política y disciplina social impuesta por las armas, los Chicago Boys tuvieron libertad absoluta para implementar sus nuevas políticas económicas (Undurraga, "Neoliberalism..." 1620) . Sin embargo, con el retorno a la democracia los gobiernos optaron por mantener el modelo con muy pocos cambios (Silva, "Technocrats..." 405; Undurraga, "Neoliberalism..." 21-27; Winn 49-50).

Así, la democracia chilena actual es una neoliberal basada en una economía de libre mercado que ha provocado profundos niveles de desigualdad. De acuerdo con el Banco Mundial, Chile es el séptimo país más desigual del mundo y quinto en América Latina (World Bank Group 84). En efecto, en Chile, imperan condiciones de vulnerabilidad laboral, la influencia de los sindicatos es impresionantemente débil y la participación de los trabajadores en huelgas en las últimas décadas ha sido mínima (Moulian 100-103; Undurraga, “Neoliberalism..." 27). 
El modelo económico heredado de la dictadura ha fomentado también el consumismo y el endeudamiento de la gente, los que contribuyen a su vez a la subyugación laboral cuando los trabadores se ven enfrentados a la necesidad de aceptar condiciones laborales deficientes, con el fin de conservar un salario que les permita no solo ganarse la vida, sino también cumplir con sus compromisos financieros. Al respecto, según datos de la Fundación Sol publicados en 2019, en Chile el 82\% de los mayores de edad está endeudado y el $26 \%$ tiene deudas morosas, contrayendo nuevos compromisos financieros para pagar los anteriores; mientras que en los segmentos de menores ingresos, las personas se endeudan con el comercio retail para comprar comida, educación, salud y ropa (Fundación Sol s/p).

En la democracia neoliberal chilena, el poder permanece del lado de las empresas nacionales y transnacionales. Prolifera la privatización de la salud, la educación, los servicios básicos y del transporte. Los recursos naturales se sobrexplotan para el beneficio de transnacionales, los pueblos originarios se reprimen y predomina la centralización, lo que ha llevado a que en un país de alrededor de 17 millones de personas y más de 4 mil kilómetros de largo, cerca de 6 millones de habitantes vivan en la capital. El costo de vida se encarece de manera regular, mientras que los salarios de la mayoría de los trabajadores y particularmente de las pensiones (excepto las de las fuerzas armadas) no se condicen con los costos de vida.

Esta transición chilena hacia una democracia neoliberal produjo un trauma social que también impactó en la literatura, la que se vio forzada a abandonar la posición de privilegio de la que alguna vez gozó y entró en lo que Avelar denomina una situación de "guetoización irreversible" (Avelar 315). La reforma universitaria de 1967 había promovido los movimientos culturales en general y la crítica literaria en particular, puesto que "la literatura y la crítica literaria parecían inseparables de la construcción de una nueva sociedad" (64). Pero ello cambió drásticamente con el golpe militar y la dictadura, ya que Chile pasó de tener un Estado que regularmente patrocinaba las artes a evidenciar un "apagón cultural", término con el que se conoce el desmantelamiento de la escena cultural promovido por la dictadura hacia mediados de la década de 1970, cuando la mayoría de los artistas, escritores y críticos literarios vivían en el exilio, estaban presos, desapa- 
recidos, silenciados, muertos o forzados a trabajar bajo las condiciones del mercado.

En dictadura, los espacios dedicados al estudio de las humanidades $\mathrm{y}$ al desarrollo de expresiones culturales e intelectuales fueron intervenidos por los militares y las universidades pasaron de formar humanistas y administradores públicos con un fuerte sentido ideológico a formar tecnócratas (Alvear 48-66). Jon Beasley-Murray destaca que, a primera vista, el neoliberalismo da la falsa impresión de basarse solo en discursos técnicos y no ideológicos. Sin embargo, tal supuesto silencioso es su principal fuerza política. Por ende, su estudio desde cualquier disciplina necesita de "una perspectiva histórica que comprenda la transición democrática no como el nuevo comienzo o la pizarra en blanco que sus arquitectos proponen, sino dentro del contexto de, al menos, los últimos 30 años de la historia chilena" (Beasley-Murray 3233). Asimismo, para el estudio de la literatura chilena más reciente y emergente, los determinantes sociopolíticos sobre los que se funda, los que hereda y a los cuales interpela son ineludibles, independientemente de las perspectivas y posiciones variadas con las que puedan contribuir los distintos autores.

\section{Eltit y Fuguet como representativos de la literatura chilena de la postransición}

En el contexto previamente descrito de democracia neoliberal chilena es posible postular a la literatura publicada en Chile a partir del año 2000 como representativa de la literatura chilena de la postransición. Esto es, una literatura que comparte el legado social, político e histórico expuesto y que proyecta y (re-)crea un imaginario social permeado por el modelo político-cultural neoliberal del Chile contemporáneo, el que fuera impuesto por la dictadura y validado por la transición a la democracia.

Desde la ciencia política no existe acuerdo en cuanto a si la transición a la democracia chilena terminó o no (Huneeus 33-34). Sin embargo, desde una mirada literaria y cultural, siguiendo el enfoque de Avelar, es posible proponer que la transición chilena acabaría simbólicamente en 2000. Ese año no solo fue testigo del comienzo de un nuevo siglo y milenio, dejando atrás la tumultuosa historia chilena del siglo veinte, sino que además está marcado por el comienzo del primer go- 
bierno de izquierda después de la dictadura: el de Ricardo Lagos (20002006). No obstante, las políticas de la izquierda reformada que lideró Lagos favorecieron ampliamente al sector privado y consolidaron el legado político, económico y cultural de la dictadura. En este periodo, entre otras cosas, se firmaron variados acuerdos de libre comercio; no cesó la privatización de los recursos naturales y los servicios públicos; hubo una aplastante represión y acallamiento de los movimientos mapuches y estudiantiles; se invocó la ley antiterrorista de Pinochet en casos relacionados con el conflicto mapuche; se hicieron modificaciones a la Constitución de Pinochet de 1980, lo que validó en democracia una constitución creada por la dictadura; y si bien en 2004 se finalizó el Informe de la Comisión Nacional sobre Prisión Política y Tortura, conocido como Informe Valech, Lagos comprometió por cincuenta años la naturaleza secreta de los testimonios y de las identidades de los violadores a los derechos humanos, estrategia que ha impedido el uso de estos registros en los juicios.

Para continuar con este enfoque desde lo literario, discutiremos algunas nociones alrededor del estudio de la narrativa ficcional más reciente de Eltit y Fuguet. Si bien al comienzo de sus carreras estos escritores fueron considerados figuras literarias innovadoras, hoy en día, a la luz del nuevo milenio, podrían bien ser denominados autores chilenos “semicanónicos". En 2018, Eltit recibió el Premio Nacional de Literatura y ambos escritores gozan actualmente de un lugar privilegiado dentro de la esfera literaria chilena. Cuentan con un amplio reconocimiento internacional, sus obras son publicadas por editoriales establecidas a nivel mundial, han sido traducidos a distintos idiomas, ambos autores son estudiados en programas académicos en Chile y en el extranjero (quizás un poco más Eltit que Fuguet, aunque un movimiento como McOndo, liderado por Fuguet en la década de 1990 tiene espacio en casi cualquier programa o libro sobre literatura hispanoamericana), tanto el trabajo de Eltit como el de Fuguet es ampliamente reseñado en la prensa y ambos han sido invitados a exponer en universidades de prestigio nacional e internacional.

Los críticos han tendido a leer las obras de Eltit y Fuguet a través de perspectivas poscolonialistas y posmodernistas respectivamente. En el caso de Eltit, desde una perspectiva poscolonialista se ha destacado su uso de un lenguaje denso y fragmentado, el que aparentemente se resiste 
a la traducción; la fusión del español con lenguas indígenas en algunas de sus primeras novelas; el uso del sociolecto chileno de las clases bajas; y el posicionamiento de las mujeres y del "lumpen" en el centro de la narrativa ficcional como forma de desafiar los universales que silencian al subalterno, de resistir los patrones económicos neoliberales de occidente y los cánones literarios chilenos (Brito 111-142; Green 17; y Llanos 165-166). Por su lado, Fuguet ha sido tradicionalmente leído como un autor posmoderno principalmente por la influencia del neoliberalismo en su literatura, la que muestra un foco en la globalización, la tecnología, los medios masivos y la cultura pop estadounidense, además de narraciones muchas veces cargadas a la autoficción. Su obra retrata a las clases sociales altas de Chile y a la sociedad consumista e individualista que deriva de la economía de libre mercado, y mostraría un desinterés en las perspectivas ligadas a un territorio nacional e histórico en particular, así como una aparente distancia de ideologías políticas (CárcamoHuechante 165; Palaversich 40-43; Paz Soldán, "Escritura y cultura..." 44-48; Robbins y González 17).

Sin embargo, si bien tales lecturas han contribuido a determinar algunas de las características generales de los proyectos escriturales de dichos autores, desde una mirada político-cultural son limitadas en considerar los legados del contexto sociopolítico particular chileno que ha influenciado profundamente a ambos autores. Además, ellas se basan principalmente en el estudio de las obras más tempranas de Eltit y Fuguet, publicadas en la década de 1980 y 1990, sin abundante cuestionamiento a cómo se han desarrollado los proyectos de dichos autores a la luz del escenario político-cultural del nuevo milenio. De manera que, tradicionalmente, se ha leído a estos autores como representantes de esferas políticas y literarias completamente opuestas que no se relacionan entre sí: Eltit como una autora cuya escritura representa un proyecto de izquierda que intenta resistir el neoliberalismo chileno y a Fuguet como representante y promotor de ese mismo neoliberalismo, o como un autor aparentemente apolítico. No obstante, Rubí Carreño nos alerta acerca de cuán inútiles pueden ser las dicotomías tradicionales en un contexto donde la globalización ha intervenido profundamente la literatura chilena actual. Para ella, la narrativa ficcional chilena del 2000 insiste en la memoria como macrogénero mediante subjetividades colectivas disgregadas como efecto de lo que implicó la instauración de la sociedad de mercado (Carreño, “De niños...” 104-106). 
Tomando en cuenta el contexto político-cultural chileno expuesto, un acercamiento a la literatura más reciente de Eltit desde un enfoque poscolonialista - el que en América Latina implica un foco central en la relación entre fuerzas coloniales o neocoloniales, raza y etnicidad (Rabasa 219-223)—, resultaría problemático. Esto es especialmente evidente en su literatura de la postransición, donde la opresión de género y de clase no se retrata como ligada a factores raciales y económicos conectados con la etnicidad. Como resultado del neoliberalismo contemporáneo chileno, las actuales formas de opresión retratadas en novelas como Mano de obra (2002), Impuesto a la carne (2010) y Fuerzas especiales (2013) no se encuentran conectadas con un grupo étnico en particular ni con una "tierra" específica, sino con contextos urbanos y dinámicas que implican interconexiones entre clase y género en ciudades globalizadas contemporáneas. Así, los procesos político-culturales más locales y contemporáneos no pueden quedar fuera del análisis.

Montecino ha argumentado que en el contexto cultural e histórico chileno, el origen desconocido es característica del mestizo (128). Esto significa que para una parte importante de las personas rastrear sus antepasados indígenas es imposible. Esto tiene relación con la cuestión de los "enmascaramientos identitarios" (Ancán y Calfío 6), que ha tenido gran influencia en el contexto cultural chileno contemporáneo. En los extendidos procesos de migración campo-ciudad acaecidos en Chile, como una forma de evitar la discriminación muchos descendientes de mapuches (y probablemente también de otros pueblos originarios) han sucumbido a procesos de asimilación definitivos, los que han resultado en el enmascaramiento de la identidad indígena no solo a través de la pérdida de la lengua y cultura nativa, sino también en la abrumadora pérdida de los apellidos (6). Esto no quiere decir que la cultura chilena y los chilenos sean menos indígenas que en otros países latinoamericanos. Simplemente, da cuenta de por qué es insuficiente un acercamiento tradicional a la obra más reciente de Eltit enfoncándose en los factores étnicos involucrados en las nuevas formas de opresión existentes en una sociedad neoliberal urbana que ha intentado blanquear sus raíces indígenas al punto de muchas veces no poder rastrearlas.

En cuanto a Fuguet, los acercamientos posmodernistas también presentan problemas para leer su narrativa ficcional más reciente. 
Centrados en perspectivas posnacionales y la presunción de que su proyecto literario no muestra interés en debates ideológicos ni nacionales, las lecturas posmodernistas de su narrativa ficcional no pueden dar cuenta de la posición política del escritor y no entregan herramientas para analizar la ideología detrás del proyecto escritural aparentemente apolítico de novelas como Aeropuertos (2010), por ejemplo. Tampoco explican la dinámica relación entre ideología, ficción y memoria presente en obras como Las películas de mi vida (2003) y Missing (una investigación) (2009). Por lo tanto, los acercamientos posmodernistas no nos entregan la posibilidad de desvelar las diversas formas en que el lenguaje literario de la postransición neoliberal chilena puede ser "político", ni el valor político que pueden tener las lecturas más recientes del pasado. Todo lo cual constituye factores centrales para el estudio de la literatura chilena actual y emergente. Así, una lectura política de dicha literatura, cuyos determinantes están fuertemente influenciados por el neoliberalismo chileno, requiere de un acercamiento contextualizado que reconozca tanto al texto como al contexto sociopolítico sobre el cual se construye esta ficción.

Es pertinente, entonces, leer las novelas de Eltit y Fuguet publicadas a partir del 2000 como representativas de la literatura chilena de la postransición, es decir, una literatura que comparte el legado sociopolítico de la dictadura chilena y (re-)crea un imaginario social permeado por el proyecto político-cultural impuesto por los militares y consolidado por la transición a la actual democracia neoliberal chilena. Ello, porque una aproximación interdisciplinaria y contextualizada a autores como Eltit y Fuguet que incorpore perspectivas históricas, políticas, culturales y literarias ilumina el estudio de las herencias y los efectos de la literatura chilena de la postransición. También da cuenta de las variadas formas que tiene esta literatura de ser política, es decir, del rol que le cabe en la construcción de un cierto imaginario social de la postransición chilena. Esta aproximación combina productivamente una lectura enfocada tanto en la forma narrativa como en sus determinantes sociopolíticos para mostrar cómo estas son utilizadas en contextos históricos específicos, con una mirada que preste atención a las implicancias ideológicas detrás de ese uso (Keen 50-52). Es una metodología que reconoce la significancia de las conexiones sociopolíticas de la literatura chilena de la postransición y 
de las decisiones literarias que toman los autores para retratar un determinado universo ficcional, perspectiva que puede establecer cómo dos autores aparentemente disímiles como Eltit y Fuguet construyen representaciones que se entrelazan en el imaginario social chileno de la postransición e interactúan con este, como lo graficará el siguiente análisis.

\section{Medios modernos ${ }^{2}$ de control social en Fuerzas especiales y Aeropuertos}

Dentro de las novelas más recientes de Eltit y Fuguet se encuentran Fuerzas especiales y Aeropuertos ${ }^{3}$ respectivamente, las que de momento no han sido objeto de un análisis comparado desde la visión de la literatura chilena de la postransición que aquí se propone. Para demostrar cómo ambos autores entregan en conjunto perspectivas significativas acerca del imaginario social de la postransición y el rol político-cultural que juegan dichas perspectivas en su construcción, el análisis se centrará en el foco que ponen ambas novelas en la multimedia, las tecnologías de la información y la comunicación (TIC), y las drogas.

Fuerzas especiales se ambienta en una población ${ }^{4}$ ubicada en los márgenes de la sociedad chilena contemporánea e intervenida por las policías civil y uniformada. La novela retrata la manera cruda en que los pobladores deben lidiar a diario con la violenta intromisión de la presencia armada. La población no se identifica, pero de acuerdo con lo que la misma autora ha declarado, se inspiraría en la población La Legua de Santiago que se encuentra intervenida desde 2001 (Eltit párr. 13). En cuanto a Aeropuertos, la novela nos relata la historia de dos

\footnotetext{
2 En este artículo, el término "moderno/a", se refiere a "Perteneciente o relativo al tiempo de quien habla o a una época reciente" (Real Academia Española, Diccionario de la lengua española).

$3 \quad$ El análisis hace referencia en el caso de Fuerzas especiales, a la edición publicada por la editorial Planeta en su colección Seix Barral Biblioteca Breve (2013); y en el caso de Aeropuertos, a la edición publicada por Alfaguara también en Santiago de Chile en 2010. Las citas subsiguientes a ambas novelas contendrán solo el número de página entre paréntesis.

${ }^{4}$ El término "población" se refiere a barrios de clase baja y socialmente estigmatizados. En Chile, estos pueden tener orígenes formales o informales, a veces son el resultado de proyectos de vivienda social impulsados por los gobiernos, o bien, se trata de tomas de terrenos hechas por los mismos pobladores.
} 
jóvenes adolescentes de las clases altas del Santiago de los años 1990 y 2000 que se convierten en padres a temprana edad, y la manera en que tanto los padres como el hijo lidian con las consecuencias de una paternidad no deseada. En ambas novelas, la multimedia y las TIC forman parte esencial de la vida diaria de los personajes, más allá de las clases sociales disímiles que retratan ambas historias.

En Fuerzas especiales, la presencia de la tecnología cumple dos propósitos. Por una parte, su uso se lee como el escape de una realidad cruda y violenta, y por otra, como una fuente de conocimiento e información abierta a personas con escasa educación formal. Esto es evidente en el siguiente ejemplo:

Cómo complacerla o cómo ayudarla, pienso, pero me distraigo en uno de mis sitios preferidos que da inicio a la nueva temporada de zapatos manufacturados con la piel de una serpiente que habita el norte argentino, la lampalagua. Estos diseños, los más elegantes que he visto, ya se han apoderado de las superlativas vitrinas francesas. (29)

Estas palabras reflejan el registro lingüístico de la narradora-protagonista de Fuerzas especiales, el que es formal, culto y permeado de información que obtiene desde los distintos sitios web que acostumbra visitar en el cibercafé donde se prostituye. Nos muestra que en la vida moderna, la multimedia y las TIC se encuentran ampliamente disponibles en contextos vulnerables y que también pueden tener propósitos contradictorios. En el ejemplo, por un lado, la tecnología se puede leer negativamente como un entretenimiento banal que interviene con el proceso de reflexión que la protagonista lleva a cabo en torno a la desmejorada situación que enfrentan ella y su familia. Vinculado con la economía de libre mercado a la que alude la novela, el ejemplo nos recuerda la sobreexplotación de los recursos naturales (en este caso de especies nativas sudamericanas) con fines comerciales. La falta de una mirada crítica a este fenómeno por parte de la narradora acentúa la idea de la tecnología como elemento distractor, en donde el contenido que se ofrece (la moda) no pareciera motivar en ella ningún afán crítico, idea sustentada por la forma narrativa. El proceso de reflexión inicial de la protagonista cede paso al frenesí de la prosa que desvía su atención hacia la descripción apresurada de banalidades relacionadas con la moda, también pasajera por cierto. No obstante, 
esta especie de boicot al pensamiento crítico de la protagonista parece quedarse en el ámbito del contenido que le ofrece el dispositivo tecnológico en ese momento: la moda que pasa tan rápido como la atención que ella le presta (no sin deslizar así una cierta crítica a las malas prácticas de esta industria). La forma narrativa del ejemplo realza más bien la naturaleza reflexiva de la narradora-protagonista. El énfasis en el término "pienso", con su ritmo calmo y su posición en primer plano separado por comas, plasma la naturaleza pensante de esta pobladora y la aísla de la distracción rauda o pasajera que le provoca el contenido de la tecnología.

El acceso a la tecnología y a los dispositivos tecnológicos no es solo común en una sociedad chilena moderna, consumista, globalizada y neoliberal, sino que en la novela además se presenta como una importante forma de escape y resistencia a la represión que viven a diario los pobladores. Otro ejemplo lo encontramos en la voz de la narradora cuando reflexiona acerca de la brutal golpiza que recibió su padre por parte de la policía: “Tengo que buscar en alguno de los sitios de huesos para comprender cómo reaccionaron sus costillas al lumazo o en qué lugar se incrustó la quebradura" (50). Estas palabras muestran a una narradora-protagonista intelectualmente curiosa y con ansias de conocimiento. Fuerzas especiales cuestiona la imagen prejuiciosa tradicionalmente instaurada en el imaginario social contemporáneo que ve a los pobladores como gente ignorante, delincuentes y desinteresados del pensamiento crítico. La lectura en línea a la que la protagonista dedica su tiempo libre, en el mismo locus donde debe soportar el abuso sexual para poder llevar el pan a su casa, es un símbolo de resistencia contra un sistema que, en tiempos contemporáneos, busca controlar de forma opresora a las clases vulnerables, incluso por la fuerza. De tal modo, la novela sugiere que no es la ignorancia de los pobladores la que los mantiene sumisos al sistema opresor, sino que es la fuerza brutal de la represión que ejerce dicho sistema la que los mantiene marginados en el sofoco de la pobreza, los abusos laborales y la violencia de las instituciones del Estado. En este contexto, sin embargo, la tecnología puede eventualmente llevar a las clases oprimidas a reflexionar críticamente en torno a su situación mediante procesos de autoeducación. Así, una lectura enfocada tanto en la forma como en los determinantes sociopolíticos a los que la novela hace eco permite entender el uso de la multimedia y la tecnología por parte de Fuerzas 
especiales como una herramienta con un cierto potencial social: una fuente de información disponible a lo largo de los distintos sectores de la sociedad, incluso los marginados, y por ende, eventualmente útil en el desarrollo del pensamiento crítico inherente a los seres humanos.

Otro ejemplo del uso de la multimedia y las TIC que hace la novela se encuentra hacia el final de la historia, cuando la protagonista y sus amigos se digitalizan y pasan a ser personajes de un videojuego que ellos mismos han creado. El juego se trata de pelear contra policías; la narradora nos dice "Y entonces aparecemos en la pantalla con el título que diseñamos: <<Pacos Kuliaos>>” (165). Si bien virtual, este es un notable intento de resistencia evidente no solo en la temática del videojuego sino que es, de nuevo, subrayado por la forma, la que incluye una ortografía alternativa al término "culeado". Esta forma alternativa de escritura más el marcado insulto que representa esta frase, producen un contraste entre el registro lingüístico mayoritariamente formal y culto que utiliza la narradora-protagonista a lo largo de la novela y el que lanza en este ejemplo. Dicho contraste en la forma narrativa es significativo, pues se produce en el espacio virtual del computador. En este espacio imaginario, el uso de la tecnología permite que la narradora haga uso de un lenguaje "de la calle", hablado, coloquial, fuerte, agresivo y desafiante. Le permite además conducir a los lectores a ese espacio insurgente para acompañarla en su rebeldía, reproduciendo en la mente el clásico insulto hacia la policía chilena: "Pacos Kuliaos". Esto demuestra nuevamente que la forma literaria de la novela viene a subrayar las preocupaciones político-culturales de su contenido, recalcando el potencial de resistencia de los pobladores. A través de su forma narrativa, Fuerzas especiales resalta la capacidad de rebelión de su narradora-protagonista al poner en primer plano su naturaleza pensante y su capacidad creadora y creativa, lo que sugiere el potencial de un liderazgo femenino lleno de fuerza insurgente.

El videojuego que crean estos pobladores acarrea connotaciones sociales no solo al permitir la resistencia de estos personajes que viven bajo represión, sino también al representar una forma de innovación creada por personajes que viven en los márgenes de la sociedad. Tal y como lo explica la narradora, es "el primer video juego chileno. Un veloz juego de defensa diseñado por el Lucho, musicalizado por el Omar y perfeccionado por mí" (165). Esta innovación digital parece hacer un 
guiño a otro especial invento chileno en el área de las TIC: el proyecto Cybersyn.

Desarrollado durante el gobierno de Allende en 1971, este proyecto cibernético buscó construir un sistema de apoyo para la toma de decisiones gubernamentales que gestionara de manera cooperativa y coordinada la nueva economía socialista. A pesar de que en aquel entonces Chile era uno de los países latinoamericanos con menos herramientas tecnológicas, el proyecto Cybersyn contemplaba cuatro módulos de alta complejidad tecnológica para la transferencia de datos y generación de informes casi en tiempo real: un simulador económico que predecía los posibles impactos de decisiones en materia económica; un software diseñado por programadores chilenos y británicos que analizaba el desempeño industrial; una sala de operaciones con aspecto futurista en las oficinas centrales del gobierno en Santiago; y una red nacional de télex distribuidos en empresas estatales que transmitían información a un computador central y también recibían datos desde este (Ortíz et al., "The Cybersyn..." 12-14). La participación del pueblo y de los trabajadores se contemplaba en cada etapa del proyecto, pues Allende apuntaba a llevar a cabo cambios estructurales sin poner en riesgo la estabilidad de las instituciones democráticas existentes en el país, en una especie de equilibrio entre el control centralizado y la libertad individual (Medina 30). Como parte de este proyecto, el experimento Cyberfolk ofreció a las personas conexión a distancia en tiempo real con políticos y administradores del Estado que discutían asuntos concernientes a sus comunidades. A través de un dispositivo especial, las personas tenían incluso la posibilidad de votar en relación con dichos asuntos (91-98). También gracias a esta tecnología y la cooperación de trabajadores leales al gobierno socialista, este pudo manejar con éxito la continuidad de la producción y el abastecimiento durante el "paro de los patrones" o "paro de los camioneros" de 1972 (150).

El guiño que Fuerzas especiales hace al proyecto Cybersyn respecto de la utilización de las TIC y la multimedia por parte de un país socialista emergente con recursos tecnológicos limitados y con fines políticos democráticos, se condice con el potencial social que la novela sugiere en el uso de estos mismos elementos por parte del pueblo. Tanto el proyecto Cybersyn como el videojuego creado por la narradora- 
protagonista y sus amigos son potencialmente poderosos en las manos de estos pobladores que viven bajo el sofoco de la represión policial del Chile contemporáneo. En ambos casos se demuestra que cuando la tecnología se pone a disposición de las bases, puede convertirse en una fuente de participación y organización social democrática, así como en un espacio para el desarrollo de nuevas formas creativas de agencia y resistencia contra las fuerzas del poder.

Por su parte, en Aeropuertos la multimedia y las tecnologías de la información tienen igualmente una presencia primordial. Esto se evidencia no solo en la trama, sino también en su forma narrativa, la que podría denominarse "híbrida", pues incorpora técnicas tradicionales como un narrador en tercera persona, discurso libre indirecto y comentarios del narrador omnisciente, además de una prosa ultramoderna con técnicas influenciadas por la multimedia y las TIC, como es la transcripción de monólogos de videos guardados en un pendrive que relatan escenas con toques cinematográficos. En un evento ambientado en 2008, Pablo, el hijo adolescente de la pareja protagonista que pasa sus días encerrado en sí mismo e inserto en las entretenciones que proveen los dispositivos tecnológicos, le deja a su madre dos videos tipo carta suicida moderna, titulados "despedidal_ciber.mov" y “2_pablo good-bye pieza.mov". Estos videos son presentados por la novela (136-153) en un formato híbrido inventado: como archivo electrónico en papel impreso, que es una mezcla de archivo de texto con audiovisual.

Al dejarle a su madre un video suicida en vez de una tradicional carta, Pablo encuentra una forma creativa de controlar cuidadosamente la imagen que desea transmitirle a ella y así lograr conmoverla. Esta imagen es la de un adolescente de catorce años desesperado, medio drogado y medio borracho, que por momentos incluso detiene su discurso para consumir "frente" a su madre, cuando en realidad está solo en una habitación y separado de ella por la pantalla. Aquí, la tecnología alude a la sociedad individualista en la que los personajes están inmersos y, paradójicamente, evidencia la desconexión existente entre madre e hijo, a pesar de que pertenecen a generaciones no tan distintas (ella fue madre a los dieciséis años) y siempre han vivido juntos. El uso de recursos digitales en la técnica narrativa refuerza el retrato de un adolescente solitario, insocial, recluido en su mundo vir- 
tual y atribulado, y nos deja con la impresión de un contexto familiar indolente, puesto que el joven necesita recurrir a formas alternativas y creativas, permitidas por la multimedia y la tecnología, para poder alcanzar emocionalmente a su madre y transmitirle sus sentimientos más honestos, crudos y profundos.

En estos videos, si bien Pablo se refiere explícitamente a sus intenciones suicidas, también le dice a su madre frases como " $i$ Me apoyas? / Apóyame" (150) y "Sígueme. Tómate tu tiempo, ahora o después, analízalo" (152). Con estas frases, el retraído e insociable joven parece estar pidiéndole algo a ella; sus palabras apuntan al deseo de que su madre le preste atención, lo acompañe, lo apoye, esté a su lado y le ayude así a sobrellevar la compleja situación de inestabilidad emocional que enfrenta a tan temprana edad, que lo hace incluso no desear vivir. En un contexto sociocultural de individualismo, el joven Pablo busca una manera creativa de alcanzar a otra persona emocionalmente significativa para él, con el fin de conseguir su apoyo. De hecho, el pendrive que le deja a su madre es blanco, está envuelto en una cinta de satín negro e incluye una nota que dice “ÁBRELO! Urgente! P." (135). Aquí, la forma también recalca las intenciones del joven. A partir del énfasis de las letras mayúsculas, del signo de exclamación y de la urgencia se puede inferir que el adolescente está gritando por el acompañamiento de la madre. Y si bien la cinta que lo envuelve es negra $-y$ por lo tanto posiblemente un símbolo de luto-, el contraste entre el blanco del pendrive y el negro de la cinta se puede interpretar como un signo de esperanza: el contenido del pendrive, al ser acogido por la madre, conlleva luz y esperanza versus la oscuridad del color - de la apariencia- que lo cubre.

Por ende, el pendrive se puede leer como un regalo de Pablo a su madre que le advierte de los peligros de la inestabilidad emocional del joven, algo que ella no está siendo capaz de ver debido al contexto individualista y de separación, más que de unión en el que están insertos ambos. Aún más, en el pendrive hay también grabado un documento Word explicativo en el que Pablo escribe "El video habla — creo- por sí solo" (135). A partir del realce de la palabra "creo" también podemos inferir la esperanza del muchacho, quien parece esperar algo a partir del descubrimiento del pendrive y su contenido por parte de su madre. Presumiblemente, que el video sea suficiente para que ella le preste 
atención y lo detenga, para que lo ayude a querer seguir viviendo. Este intento de generar conexión entre él y su madre también es acentuado cuando el otrora indiferente y ensimismado adolescente expresa abiertamente su comprensión ante el hecho de que la madre lo tuvo y crio sola siendo muy joven (151).

Otro ejemplo del uso de la multimedia y la tecnología se da al final de la novela cuando un huraño Pablo se reencuentra con su padre, con quien nunca tuvo una relación cercana (173-183). En medio de una conversación ambigua e incómoda entre padre e hijo, repentinamente cuenta el narrador que Pablo "lo abraza y con su iPhone se toma una foto" (181). Si bien este es un acercamiento meramente virtual (ambos siguen sin tener una relación cercana) que hace recordar que la novela se ambienta en una sociedad consumista e individualista en donde las personas se unen a través de dispositivos tecnológicos más que por medio de relaciones humanas profundas, el reencuentro final entre padre e hijo revela también las cosas en común que tienen ambos, esto es, el entusiasmo por la cultural digital y la multimedia, especialmente la música pop, el cine y los dispositivos tecnológicos que permiten compartirlos y difundirlos (170). Esto habla otra vez de los propósitos ambiguos y contradictorios de la multimedia y la tecnología. Por una parte, pueden ser un medio para evadir a las personas de su realidad y que vivan enfocados en un mundo virtual que aparenta relaciones humanas que en el mundo real no existen; Aeropuertos representa una sociedad individualista que carece de interacciones humanas significativas, incluso cuando existen lazos familiares más cercanos. Pero, por otra parte, pueden ser también una herramienta que permite encontrar formas creativas e innovadoras de unir a las personas y reconectarlas.

La técnica narrativa híbrida de la novela, que deambula entre elementos tradicionales y ultramodernos, viene a reforzar las ambigüedades y contradicciones que plantea la historia en sus referencias a la multimedia y la tecnología en cuanto a las relaciones humanas de las que carecen los protagonistas. Estas contradicciones plantean las mismas ambigüedades de la sociedad que retrata Aeropuertos. Una sociedad moderna, consumista e individualista en donde los dispositivos tecnológicos parecen haberse instalado con importancia irrevocable en la vida de las personas, quienes sin embargo se ven en la necesi- 
dad de buscar relaciones humanas más esenciales y, por consiguiente, encontrar formas creativas para alcanzar y reconectar con otros, tarea donde la tecnología eventualmente puede jugar un rol central.

Si bien desde perspectivas socioeconómicas diferentes, tanto en Fuerzas especiales como en Aeropuertos el uso de la multimedia y las TIC sugiere que dichos elementos pueden acarrear un doble propósito. Desde el lado negativo, ser un medio de control social para evadir a las personas de las miserias de su mundo real, alejarlas entre sí y evitar de tal modo la eventual insurgencia social. Y, desde el positivo, contener potenciales sociales, entre ellos: la autoeducación, el liderazgo desde lo creativo y el desarrollo de pensamiento crítico como lo sugiere la novela de Eltit, y como se desprende de ambas obras, un medio para generar formas innovadoras y creativas para alcanzar la necesaria transmisión y difusión de mensajes de resistencia a un sistema neoliberal que no escatima en esfuerzos para mantener a las personas desconectadas entre sí con fines de control social. Si bien los usos que se pueden hacer de ella son ambiguos, una mirada conjunta a estas novelas de la postransición nos revela que la tecnología podría servir para reconectar a los seres humanos y transmitir emociones, significados y mensajes esenciales para la subsistencia de las personas y, en particular, de las nuevas generaciones. Esto es, ser potencialmente una vía para una resistencia que utiliza los mismos medios modernos de control social con los que el neoliberalismo ha bombardeado a la sociedad chilena de la postransición.

Sin embargo, es importante matizar que en ambas novelas, tales potenciales se ven mermados por la fuerte presencia de las drogas que alejan a los personajes de la realidad y los mantiene adormecidos y sedados. Las drogas, tanto legales como ilegales, tienen una presencia abrumadora en los ambientes que retratan ambas novelas. En Aeropuertos abundan las instancias en las que padre, madre e hijo necesitan consumir drogas, alcohol y pastillas para dormir para enfrentar la depresión que les produce la vida desolada e infeliz que llevan. Uno de esos ejemplos es el antes analizado caso de los videos que el hijo adolescente graba para su madre, donde se muestra ante ella drogado y alcoholizado y, hacia el final de la novela, los tres protagonistas permanecen unidos por la característica común del consumo de drogas legales e ilegales $(162,163,176)$. De este modo, la novela muestra la 
contradicción detrás del hecho de que ciertas libertades modernas - como el acceso a los bienes de consumo que puede comprar una posición acomodada-, los privilegios económicos y el amplio acceso a la tecnología y a las drogas pueden no ser más que formas sutiles y modernas de control social.

De igual modo, aunque desde otra perspectiva socioeconómica, Fuerzas especiales retrata un contexto similar. La narradora nos cuenta que en una noche de sábado, "Los bloques, volcados a aspirar, deberían amplificar la música neoprenera del amanecer mezclada con una serie ordenada de brillantes jeringas de alcohol y de lágrimas hasta alcanzar el éxtasis mítico" (42), palabras que resaltan los vicios tóxicos de la vida moderna que llevan estos pobladores. Y agrega, "me muevo delicadamente mientras la jeringa que sostiene mi pelo relumbra a la manera de un láser que prueba en mi cabeza su última tecnología de facturación china" (42). En esta imagen de la protagonista se aprecia su dependencia tanto de la droga que contiene la jeringa como del sistema que la facilita, que ha creado esta jeringa, o drogodependencia, con "tecnología de facturación china". Aquí se hace referencia al capitalismo comunista de la potencia mundial china, la que se vincula también con el hecho de que la protagonista y otros pobladores son tanto proveedores de servicios, como consumidores de tecnología, drogas y alcohol. Es decir, están inmersos en un sistema laboral complejo que incluye abuso, explotación y consumismo y que los mantienen en una dependencia de la que no pueden escapar. La novela sugiere - tal como Carreño lo ha indicado ya-, que en los complejos sistemas contemporáneos de relaciones económicas y políticas, las formas modernas de control social y represión difuminan la más tradicional dicotomía política izquierdaderecha, sugerencia evidente en la alusión a la manufactura china que si bien comunista, es de un Estado productor impulsado por las leyes del mercado, un exportador que se beneficia de la globalización neoliberal y se sustenta en el consumismo occidental.

Tanto en Fuerzas especiales como en Aeropuertos la representación del uso de drogas legales e ilegales, en cuanto fenómeno que trasciende las clases sociales, deja una mirada pesimista de la sociedad chilena de la postransición, lo que representa otra herencia de la dictadura. En su estudio Pinochet: The Politics of Torture, Hugh O'Shaughnessy (2000) revela en detalle las múltiples conexiones que tenía la dictadura 
de Pinochet con el negocio de la droga a nivel nacional e internacional, lo que permitió que esta proliferara tanto en los barrios marginales como en los sectores altos de la sociedad. Así, en el imaginario social de la postransición (re-)creado por estas obras, las drogas y el propósito negativo que deslizan acerca del uso de la tecnología muestran los medios modernos de control social por parte de las esferas de poder contemporáneas.

Una lectura de la narrativa ficcional más reciente de Eltit y Fuguet desde la perspectiva propuesta desvela, entonces, algunos asuntos político-culturales comunes en los retratos de las distintas clases sociales. El análisis sugiere que la separación de clases tradicionalmente pensada como infranqueable puede no serlo tanto en ciertos aspectos culturales característicos de la postransición chilena. La desigualdad en Chile y la separación de clases que esta produce ha sido ampliamente abordada por las ciencias sociales (Mac-Clure et al., "Desigualdad..." 169-170; Salazar 113-114), así como también ha sido un fenómeno muy representado en la literatura chilena. Algunos ejemplos incluyen La casa de los espiritus (1982) de Isabel Allende (1942-) y Coronación (1957) y Este domingo (1966) de José Donoso (1924-1996), obras que retratan la gran brecha de clases sociales no solo en términos económicos, sino también culturales. Sin embargo, el análisis llevado a cabo muestra que distintas clases sociales están entrampadas en un contexto cultural similar. Este fenómeno acarrea consecuencias político-culturales por cuanto las clases obreras y la alta sociedad se encuentran bajo el control social de una combinación de fuerzas nacionales y multinacionales, del Estado y del mercado, mediante herramientas de control como la multimedia, las TIC, y las drogas legales e ilegales. Si bien esto es un legado de la dictadura que implementó el modelo neoliberal reinante en Chile por medio de las armas, actualmente las fuerzas que ejercen el control social están formadas por poderes económicos y por instituciones del Estado democrático.

En ambas novelas se lee claramente la forma en que personas de distintas clases sociales permanecen simbólicamente silenciadas, sedadas y alejadas de la realidad; entrampadas en un mundo virtual creado por fuerzas poderosas con fines de lucro y de disciplina social. De tal manera, la ciudadanía es relegada a una posición alejada de su condición humana, esto es, de las condiciones en las que se desarrolla 
su vida diaria, su trabajo y sus relaciones con los demás. Está entonces menos consciente de la manera en que se vulneran sus derechos y es abusada por un sistema de libre mercado que protege los intereses de los poderosos en desmedro del bienestar de la mayoría, y que intenta por sobre todo mantener el statu quo. Al estar las personas menos conscientes del desmejorado estatus político en el que viven, no estarían entonces preparadas para luchar, para resistir a este complejo sistema que despliega todas sus armas con tal de evitar la insurgencia social que podría devenir en su derrumbamiento.

Con todo, el uso que hacen las novelas estudiadas de la multimedia y las TIC, y su apabullante presencia a lo largo del imaginario social que (re-)crean arroja luces sobre potenciales vías para resistir dichos objetivos del sistema y reconstruir lazos comunitarios. También ilumina el rol político-cultural que juega el lenguaje literario en esta tarea, en el contexto de una sociedad chilena neoliberal que ha heredado de la dictadura y de la transición una marcada despolitización y descolectivización con consecuencias no solo a nivel comunitario, sino también en lo literario.

Baczko dice que "los imaginarios sociales operan todavía más vigorosamente en la producción de visiones del futuro, en especial en la proyección de obsesiones y fantasmas, de esperanzas y de sueños colectivos" (Baczko 30). Se puede decir, entonces, que el uso de la multimedia y las TIC en Fuerzas especiales y Aeropuertos pone un foco en el rol que estas pueden cumplir en una sociedad moderna y globalizada, como nuevas formas de autoeducación y de generación de maneras creativas e innovadoras de resistencia, reconexión y eventual organización desde las bases, ya sea socialmente o desde cada individuo. El rol que podrían cumplir como una herramienta de conexión entre las personas y entre estas y su realidad, uniéndolas y eventualmente transmitiendo entre ellas significaciones ligadas con sentimientos profundos e información es esencial para la vida de las personas, lo que puede acarrear importantes potenciales político-culturales.

Por ejemplo, en octubre de 2019, en el más reciente levantamiento de la ciudadanía chilena contra las injusticias sociales que el Estado ha promovido por más de cuatro décadas, el acceso amplio a la multimedia y las TIC jugaron un rol fundamental. Las redes sociales fueron la plataforma que permitió conectar a millones de personas que enfrent- 
aban a diario las opresiones de la democracia neoliberal chilena. Motivada por un alza en la tarifa del metro, la gente se organizó vía redes sociales para llevar a cabo evasiones masivas en lo que fue el inicio de lo que el historiador Gabriel Salazar catalogó como "una revolución por donde se la mire" (Carvajal párr. 8). Y recordando el potencial de resistencia que sugiere el videojuego creado por los pobladores de Fuerzas especiales, es curioso notar que un senador de la República asegurara en televisión que los manifestantes se organizaban para quemar el metro "vía videojuegos" (Suazo para. 3 de 8). Así, gracias al amplio y transversal acceso a los recursos tecnológicos, a la multimedia y a las TIC que hoy en día existe, estas herramientas han cumplido la importante labor de difundir los horrores de la represión y las violaciones a los derechos humanos que el Estado chileno democrático y neoliberal lleva a cabo a casi 20 años del fin de la dictadura. Las plataformas virtuales han servido no solo para que la prensa alternativa difunda la información acallada por la prensa tradicional, sino también como punto de conexión entre las personas y entre estas, la prensa alternativa y las organizaciones cuyo rol es proteger los derechos humanos.

Como queda demostrado por el análisis de las novelas, los legados y las consecuencias de los fenómenos político-culturales propios de la postransición chilena no les son ajenos a la literatura chilena del nuevo milenio de Eltit y Fuguet, la que desde distintos espacios pone en primer plano la herencia político-cultural de la dictadura que fuera ampliamente validada por la transición hacia la democracia chilena actual. Esto da cuenta de las posibles lecturas políticas y conjuga el lenguaje literario con sus determinantes sociopolíticos en dos autores chilenos aparentemente disímiles. Aquí, la dinámica relación de mutua retroalimentación entre literatura e imaginario social se prueba de una significancia política crucial.

Recordando las palabras de Baczko, solo existe comunicación entre las personas por medio de símbolos exteriores a los estados mentales individuales, de representaciones colectivas en lo imaginario y en lo simbólico (Baczko 21-30), símbolos y significaciones que la narrativa ficcional de Eltit y Fuguet transmite tanto en su forma como en sus vínculos con ciertos determinantes sociopolíticos. Y significativamente, en el imaginario social al que contribuyen las obras de la postransición analizadas, las posibles vías de resistencia se tornan imaginarias, en- 
marcadas en lo virtual, relegadas al espacio de lo creativo. Es así como las distintas formas de lenguaje literario que emplean estas novelas, junto con los contenidos y mensajes que vehiculiza su forma narrativa, hablan no solo de preocupaciones propias de sus determinantes sociopolíticos, sino que además reposicionan la significancia política de la literatura chilena. Es en este espacio creativo literario desde donde la resistencia y conexión entre seres humanos se pueden imaginar, diseñar, crear, perfeccionar y ejecutar. Contribuye así el lenguaje literario de la postransición a imaginar la forma en que la reconstrucción de lazos sociales en la sociedad chilena actual es posible. Esta literatura puede crear y diseminar un imaginario social en donde la reconexión entre personas y la insurgencia ante el sistema opresor podrían ser escenarios alcanzables, lo que demuestra el rol político-cultural que le cabe a la literatura chilena actual en cuanto a su diálogo y contribución con un cierto imaginario social contemporáneo, es decir, con las fuerzas reguladoras de la vida colectiva de la postransición chilena.

\section{Conclusiones}

Se ha propuesto aquí un acercamiento a la literatura chilena del nuevo milenio desde una mirada de la postransición, ficción para la cual sus determinantes sociopolíticos son ineludibles. Este acercamiento permite expandir las lecturas de las consecuencias político-culturales de la dictadura por un lado, pero también posibilita una mirada crítica de la transición hacia la actual democracia neoliberal imperante en Chile. El contexto desde el que emerge la literatura chilena de la postransición y al cual interpela, contempla la compleja conjugación de trayectorias políticas, históricas y culturales locales. Estas trayectorias se han traducido en formas de opresión que se basan en la interrelación de diversos factores que encuentran su origen en la influencia cultural, económica y política del neoliberalismo chileno, que es un legado de la dictadura. Este trabajo muestra que la literatura chilena de la postransición pone en primer plano sus apabullantes y sofocantes legados.

Se ha propuesto a Diamela Eltit y a Alberto Fuguet como autores semicanónicos de este tipo de literatura. Una exploración comparada a algunas de sus novelas más recientes revela que desde distintas perspectivas las obras analizadas se muestran en diálogo en cuanto a las preocupaciones que alimentan el imaginario social chileno de 
la postransición. Los mundos ficcionales retratados observan a una sociedad chilena que aún se encuentra fuertemente influenciada por los legados de la dictadura y del neoliberalismo de la transición. El análisis a las novelas revela, por un lado, los medios modernos de control social por parte de poderes ligados al Estado y al mercado, lo cual es transversal a las clases sociales y, por otro, sugiere algunos potenciales políticos detrás del amplio acceso que existe a la multimedia y a las TIC en una sociedad chilena moderna, globalizada y consumista. Así, el análisis aquí expuesto que se ha centrado tanto en una lectura del texto como del contexto, alumbra la manera en que los determinantes sociopolíticos son relevantes para la literatura chilena de la postransición y revela el rol político-cultural que juega esta literatura al contribuir dinámicamente a la creación de un cierto imaginario social de la postransición.

\section{Referencias bibliográficas}

Ancán Jara, José y Margarita Calfío Montalva. "Retorno al país mapuche: reflexiones sobre una utopía por construir". Nuke Mapuförlaget, 2002. Recuperado de https://bit.ly/2Wz5NQa

Avelar, Idelber. Alegorías de la derrota: la ficción posdictatorial y el trabajo del duelo. Santiago de Chile, Cuarto Propio, 2000.

Baczko, Bronislaw. Los imaginarios sociales. Memorias y esperanzas colectivas, segunda edición. Trad. Pablo Betesh. Buenos Aires, Nueva Visión, 1999.

Beasley-Murray, Jon. "La constitución de la sociedad: Pinochet, postdictadura y la multitud". Pensar en/la postdictadura. Ed. Alberto Moreiras y Nelly Richard. Santiago de Chile, Cuarto Propio, 2001, pp. 23-39.

Brito, Eugenia. Campos minados: literatura pos-golpe en Chile, segunda edición. Santiago de Chile, Cuarto Propio, 1994.

Cárcamo-Huechante. Tramas del mercado: Imaginación económica, cultura pública y literatura en el Chile de fines del siglo veinte. Santiago de Chile, Cuarto Propio, 2007.

Carreño, Rubí. "De niños de septiembre a pasajeros en tránsito: Memorias del 2000 en Electorat y Fuguet". Taller de letras, no. 37, 2005, pp. 103-119.

Carvajal, Claudia. "Gabriel Salazar: 'Es un hecho que la clase política es el problema que tenemos hoy"'. diarioUchile [Santia- 
go de Chile] 26 Oct. 2019: s/p. Recuperado de https://bit. ly/323GgQ7 [consultado el 31 de octubre de 2019].

Castoriadis, Cornelius. The Imaginary Institution of Society. Trad. Kathleen Blamey. Cambridge, Massachusetts, The Massachusetts Institute of Technology Press, 1987.

Eltit, Diamela. Fuerzas especiales. Santiago de Chile, Planeta, 2013a.

. "Fuerzas especiales', nueva novela de Diamela Eltit”. Entr. Carolina Rojas N. resonancias.org, 2013b. Recuperado de https://bit.ly/2JSbl39 [consultado el 31 de octubre de 2019].

Impuesto a la carne. Santiago de Chile, Planeta, 2010.

Mano de obra. Santiago de Chile, Planeta, 2002.

Fundación Sol. "Un 26 \% de los chilenos son morosos y contraen nuevas deudas para pagar anteriores". Fundación Sol, 2019. Recuperado de https://bit.ly/2WAgaDm [consultado el 1 de noviembre de 2019].

Fuguet, Alberto. Aeropuertos. Santiago de Chile, Alfaguara, 2010.

Las películas de mi vida. Santiago de Chile, Alfaguara, 2003.

Missing (una investigación). Santiago de Chile, Alfaguara, 2009.

Green, Mary. Diamela Eltit. Reading the Mother. Woodbridge, Tamesis, 2007.

Huneeus, Carlos. "La transición ha terminado". Revista de Ciencia Política, vol. 16, no. 12 1994, pp. 33-40.

Keen, Suzanne. Narrative Form, segunda edición revisada y expandida. Basingstoke, Palgrave Macmillan, 2015.

Llanos, Bernardita. Passionate Subjects/Split Subjects in TwentiethCentury Literature in Chile: Brunet, Bombal, and Eltit. Lewisburg, Bucknell University Press, 2009.

Mac-Clure, Oscar et al. "Desigualdad, clase media y territorio en Chile: ¿clase media global o múltiples mesocracias según territorios?". EURE, vol. 40, no. 121, 2014, pp. 163-183.

Medina, Eden. Cybernetic Revolutionaries. Technology and Politics in Allende's Chile. Cambridge, Massachusetts, London: The Massachusetts Institute of Technology Press, 2011.

Montecino, Sonia. Madres y huachos. Alegorías del mestizaje chileno, sexta edición. Santiago de Chile, Catalonia, 2012. 
Moulian, Tomás. Chile actual. Anatomías de un mito, tercera edición. Santiago de Chile, LOM Ediciones, 2002.

Ortiz Osorio, Henry Mauricio y José Díaz Nafría. “The Cybersyn Project as a Paradigm for Managing and Learning in Complexity". Systema, vol. 4, no. 2, 2016, pp. 10-19.

O'Shaughnessy, Hugh. Pinochet: The Politics of Torture. New York, New York University Press, 2000.

Palaversich, Diana. De Macondo a McOndo: senderos de la postmodernidad latinoamericana. México, D.F., Plaza y Valdés, 2005.

Paz Soldán, Edmundo. "Escritura y cultura audiovisual en 'Por favor, rebobinar' de Alberto Fuguet”. Latin America Literary Review, vol. 30, no. 59, 2002, pp. 43-54.

Rabasa, José. "Poscolonialismo”. Diccionario de estudios culturales latinoamericanos. Ed. Mónica Szurmuk y Robert Mckee Irwin. México, D.F., Siglo XXI Editores, 2009.

Real Academia Española. Diccionario de la lengua española. Recuperado de https://dle.rae.es [consultado el 31 de octubre de 2019].

Robbins, Timothy y José Eduardo González (Ed.). New Trends in Contemporary Latin American Narrative. Post-National Literatures and the Canon. New York, Palgrave MacMillan, 2014.

Salazar, Gabriel. Movimientos sociales en Chile. Trayectoria histórica y proyección política. Santiago, Uqbar Editores, 2012.

Silva, Patricio. "Technocrats and Politics in Chile: From the Chicago Boys to the CIEPLAN Monks". Journal of Latin American Studies, vol. 23, no. 2, 1991, pp. 385-410.

Suazo, Camilo. “Ossandón afirma que quienes quemaron estaciones del Metro se organizaron a través de los videojuegos". Biobiochile.cl, 2019. Recuperado de https://bit.ly/2PzYK8f [consultado el 31 de octubre de 2019].

Thompson, John. Studies in the Theory of Ideology. Los Angeles, California University Press, 1984.

Undurraga, Tomás. "Neoliberalism in Argentina and Chile: Common Antecedents, Divergent Paths". Revista de Sociologia e Politica, vol. 23, no. 55, 2015, pp. 11-34.

Winn, Peter (Ed.). Victims of the Chilean Miracle. Workers and Neoliberalism in the Pinochet Era 1973-2002. Durham, Duke University Press, 2004. 
World Bank Group. "Taking on Inequality", 2016. Recuperado de https://bit.ly/2WwV4We [consultado el 1 de noviembre de 2019]. 